\title{
Incompatibility and Investment in ATM Networks
}

\author{
TIMOTHY H. HANNAN * \\ Federal Reserve Board \\ RON BORZEKOWSKI
}

Federal Reserve Board

\begin{abstract}
Incompatibility across rival systems can influence incentives to invest in product changes beneficial to the consumer. We investigate this phenomenon in the case of bank ATM networks, where the number of ATM locations is a measure of product quality and surcharge fees serve as an index of incompatibility. Using as a natural experiment the lifting of a surcharge ban in Iowa (and not in neighboring states), we find that the associated increase in incompatibility for Iowa banks caused a substantial increase in the number of ATM locations offered to customers. This effect is larger (in percentage terms) for larger banks.
\end{abstract}

\section{Introduction}

The literature on compatibility in industries with network effects notes that incompatibility across systems may influence consumer welfare in two opposing directions. On the one hand, incompatibility may harm consumers by making it harder for them to derive the benefits of "mixing and matching" the components of different systems. On the other hand, it may benefit consumers if greater incompatibility causes producers to enhance their products in ways beneficial to the consumer. In this paper, we empirically examine the latter of these effects in a setting that not only allows measurement of an important dimension of product quality, but also provides an example of an exogenous shift in incompatibility that applies to some, but not all, firms in the same industry. Such a setting is provided in the case of bank investments in automated teller machine (ATMs) that are subject to regulations regarding ATM surcharging.

In the banking industry, the depositors of one institution can use their ATM cards at ATMs of other institutions. Thus, ATM cards and ATMs form a system of complementary components that produce account transactions. When a depositor of one bank conducts a

\footnotetext{
* Contact author. Federal Reserve Board, Washington, DC 20551, (202) 452-2919. Email: thannan@frb.gov The views expressed in this paper are those of the authors and do not necessarily reflect the view of the Board of Governors of the Federal Reserve System or its staff. The authors would like to thank Robin Prager and an anonymous referee for their helpful comments and David Kite for excellent research assistance.
} 
transaction using an ATM owned by another, the depositor may incur two fees: the socalled foreign fee, levied by the depositor's own bank, and another fee, known as a surcharge, levied by the institution that owns the ATM. These fees are typically not charged when the depositor of a bank uses his or her bank's own ATM. Thus, these fees may be thought of, and used empirically, as indexes of the incompatibility of rival systems. Of these two fees, the surcharge is the most useful in econometric investigation, since the controversy surrounding it has resulted in differences in state regulation that allow it to be more easily instrumented.

As noted above, an increase in incompatibility may be associated with changes in product attributes that ultimately benefit the consumer. In industries with rapidly changing technologies, this may take the form of greater technological advance as a consequence of incompatibility. In the banking industry, however, this is most likely to take the form of greater investments in bank-specific ATM networks. ${ }^{1}$ Thus, in this application, we seek to determine if incompatibility, produced by bank surcharging, yields greater investment in bank-specific ATM networks.

We also investigate in this context whether the role of incompatibility in influencing investment in bank ATM networks differs systematically with the size of the bank's network. The literature predicts that incentives for incompatibility differ across firms and will be larger for firms with larger networks, since with compatibility, these firms lose the competitive advantage that their networks confer. ${ }^{2}$ Here, we investigate a related question - whether a shift to greater incompatibility causes banks with larger networks to invest more in ATMs than do smaller banks.

The methodology employed uses a new source of data regarding ATM deployment and exploits a "natural experiment" made possible by a court decision that was handed down in March 2002. This decision, in effect, lifted a previously existing ban on ATM surcharging in the state of Iowa. Since surcharge bans in the states neighboring Iowa (and indeed in almost all states) had been lifted many years earlier, this event allows for an examination of the effect of surcharge authority on ATM deployment in a way that controls effectively for many confounding influences.

Specifically, the statistical approach employed is that of a "difference-in-difference" analysis, wherein changes in bank-specific ATM deployment occurring in Iowa over a period in which its surcharge ban was lifted are compared to equivalently measured changes occurring over the same time period in neighboring states, where no change in surcharge restrictions occurred. This approach, though simple, avoids some potential problems inherent in alternative approaches employed to address this question. Results suggest that the authority to surcharge does indeed result in deployment of more ATMs by the banking industry. Measured as the difference in the percent change in ATM locations over time, the difference appears to be substantial, particularly for the longer time period

\footnotetext{
${ }^{1}$ This prediction does not result trivially from the fact that, under surcharging, a bank gains more surcharge revenue from an additional ATM. An additional ATM is likely also to result in less revenue from foreign fees, as the bank's depositors reduce their use of other banks' ATMs. Further, if, under surcharging, an additional ATM serves to attract depositors from other banks, then profits from non-ATM sources will increase, revenue from surcharging will fall, and revenue from foreign fees will increase as a result of this ATM-induced switching of depositors from other banks. A full model outlining these effects is available from the authors upon request.

${ }^{2}$ See, for example, Katz and Shapiro (1985) and Farrell and Saloner (1985). This finding is strongly supported in the case of bank ATMs, since larger banks are more likely to levy surcharges for use of their ATMs than are smaller banks. See Hannan et al (2003) and Hannan (2002).
} 
examined. We also find evidence that larger Iowa banks added more ATM locations, in percentage terms, than did smaller Iowa banks after lifting of the surcharge ban, all else equal. These results suggest that policy toward incompatibility must consider not only its direct effect on consumers, but also its effect on product attributes, which in this case is the convenience that banks offer consumers in the form of ATM networks.

The plan of the paper is as follows: Section 2 discusses the theoretical and empirical literature relevant to ATM deployment. Section 3 describes the nature of the difference-indifference analysis to be employed, while section 4 discusses in more detail the model to be estimated. Section 5 describes the data, while section 6 presents the results of the analysis and discusses the possibility of a confounding effect. Section 7 concludes and summarizes.

\section{$2 \quad$ Literature}

In two recent papers, Bernhardt and Massoud use spatial models to derive several propositions relevant to ATM surcharging. In the first (Bernhardt and Massoud, 2002), which treats ATM deployment as exogenous, the authors derive several implications that are consistent with observed empirical regularities: Banks set high bank account fees for their own depositors but do not charge their own depositors for use of the bank's own ATMs; in contrast, banks charge nondepositors ATM fees (surcharges) that exceed those levels that would maximize ATM revenues from nondepositors, and larger banks set higher account fees and levy higher surcharges for ATM use than smaller banks.

Of more relevance to the issue of ATM deployment, Bernhardt and Massoud (2005), in a second paper, develop a spatial model in which the number and location of ATMs are endogenous. They find that in equilibrium, banks over-provide ATMs because they extract profits more efficiently from bank members through bank account fees than from ATM use by depositors of other banks and because a more developed ATM network raises the value of establishing an account with the bank. They note that this prediction of over provision of ATMs is consistent with the observed proliferation of ATMs in recent years. Since there appears to be no incentive for a bank in their model to provide ATM services in the absence of surcharging, a positive relationship between authority to surcharge and ATM deployment appears to result trivially from their model.

Several papers have reported empirical investigations of the implication of ATM surcharging. Papers by Ishii (2005) and Knittel and Stango (2004) in particular are noteworthy, in that they derive and estimate quite sophisticated structural models. Using detailed structural estimates, they report the results of counterfactual experiments designed to assess the effects of a surcharge ban on a number of measures of interest, including market shares, deposit-account pricing, and consumer and total welfare.

Of primary interest to this paper is their treatment of the relationship between surcharging and ATM deployment. Noting the problems of multiple equilibria, Ishii does not provide explicit predictions regarding equilibrium ATM deployment. She does find, however, that with the imposition of a surcharge ban, each bank would have an incentive to decrease the size of its ATM network. Without a prediction regarding equilibrium ATM deployment, Ishii notes that her estimates of the welfare implications of a surcharge ban must abstract from the effects of any induced changes in ATM deployment. 
Knittel and Stango address this problem by conducting a separate empirical analysis of the relationship between surcharging and ATM deployment. With estimates from their structural demand model and estimates from their separate analysis of ATM deployment, they are able to provide an estimate of the effect of surcharge authority on consumer welfare, taking account of the induced changes in the size of bank ATM networks brought about by authority to surcharge.

Because Knittel and Stango's analysis of the relationship between surcharging authority and ATM deployment is an alternative to the one presented in this paper, it is useful to discuss their analysis in some detail. The data on ATM deployment that they employ are obtained from the Card Industry Directory, which indicates annually the number of ATMs of each of the 300 largest ATM card issuers. Because their analysis focuses on local markets, they estimate the number of ATMs deployed in each of these local markets by these large card issuers by extrapolating from their known distributions of branch offices.

For banks in most states (but not in Iowa), existing bans on ATM surcharging were effectively lifted April 1, 1996, when the Cirrus and Plus national ATM networks modified their operating rules to allow ATM owners to impose surcharges. Knittel and Stango's estimates of the impact of surcharging authority on ATM deployment rest on the presumption that the trend in ATM deployment observed for these 300 institutions before 1997 would have continued after 1997 in the absence of surcharging. Thus, in a regression in which the log of the number of ATMs is regressed on time and dummy variables indicating each of the three years immediately following the change, 1997, 1998, and 1999, (and also including county and bank fixed effects), the coefficients of the year dummy variables are interpreted as the effect of surcharging on the deployment of ATMs. Knittel and Stango conclude that the increase in ATM deployment was about 7 percent in 1999 as a result of the lifting of restrictions on surcharging. ${ }^{3}$ Clearly, this estimate depends crucially on the assumption that the trend in ATM deployment observed before 1997 would have continued after 1997 in the absence of surcharging.

Gowrisankaran and Krainer (2006) also report results relevant to ATM deployment. Their analysis is based on a structural model of locational or "entry" choices made among potential locations of ATMs by ATM owners. Focusing on the rural Minnesota and Iowa counties located near the boundary between those two states, they obtain estimates of fundamental utility and cost parameters from observed entry decisions and then use these parameters to evaluate policy experiments, such as the imposition of a surcharge ban. The fact that Iowa did not allow surcharging during the period examined allows them to identify the role of price in their model. Among other findings, they conclude that a ban on surcharging reduces ATM “entry” by about 12 percent. While quite innovative, this model requires some assumptions that do not appear to align well with observed bank behavior. As the authors note, their model, among other simplifications, does not "allow for banks to price discriminate by not surcharging their own banking customers, or to subsidize ATM transactions as a way of obtaining customers and charging them for other services." ${ }^{4}$ These

\footnotetext{
${ }^{3}$ Knittel and Stango also report separate estimates of the increase in ATM deployment for banks that compete in the same markets as the institutions for which data on ATM deployment are directly observable. However, their estimate (about 12 percent) for these banks is probably less reliable, since the number of ATMs assigned to these banks (many of which are small) are obtained by extrapolating from the institutions for which ATM data are available (all of which are large).

${ }^{4}$ See Gowrisankaran and Krainer (2004, p.7).
} 
two simplifications leave out much that should be quite relevant to bank decision making regarding the deployment bank ATMs.

\section{A "difference-in-difference" analysis of the effect of surcharge authority on bank ATM deployment}

The empirical approach pursued in this paper exploits the natural experiment made possible by the very different policies toward surcharging taken by Iowa, on the one hand, and the six states neighboring Iowa, on the other. As noted above, a major event in the history of surcharging occurred on April 1, 1996, when the Cirrus and Plus national ATM networks modified their operating rules to allow ATM owners to impose surcharges. Thereafter, the incidence of surcharging rose substantially in the states neighboring Iowa: Illinois, Nebraska, Minnesota, Missouri, South Dakota, and Wisconsin. According to a survey of bank fees conducted in 1999, surcharges were levied by 43 of 46 surveyed ATM-owning banks in Illinois, 8 of 11 such banks in Minnesota, 19 of 19 in Missouri, 5 of 5 in South Dakota, and 13 of 17 in Wisconsin. ${ }^{5}$ Thus, surcharging appears to have been nearly universal during this period in the states that allowed it.

In contrast to these states, Iowa maintained a ban on surcharges until March of 2002. The 1999 survey of Iowa banks produced only 3 of 18 surveyed ATM-owning banks responding that they imposed a surcharge, while the 2001 survey found only 3 of 24 such banks indicating that they surcharged. While it is unclear why a few small banks would respond that they are surcharging ATM users in a state that bans the practice, it is clear that the ban, on the whole, was effective in making surcharging a rare, if not nonexistent, practice in the state.

To assess the changes in ATM deployment brought about by surcharging, the approach taken will be to compare the changes in the number of ATM locations reported by Iowa banks over a period in which the Iowa surcharge ban was lifted with the changes occurring at the same time at banks located in neighboring states, where no change in a surcharge ban occurred. Because surcharge bans in the states neighboring Iowa were lifted well before the lifting of the surcharge ban in Iowa in March of 2002, this date represents an event surrounding which a difference-in-difference analysis can be conducted.

In assessing the results of the analysis, it will be useful to keep in mind that, in response to the lifting of a surcharge ban, the optimal levels of bank decision variables other than the surcharge or the number of ATMs deployed may also change. Banking organizations, for example, can make themselves more or less attractive to depositors by altering deposit rates and other fees, such as the foreign fee. Thus, any observed changes in ATM deployment would presumably reflect the impact of induced changes in these items as well.

\footnotetext{
${ }^{5}$ Nebraska lifted its ban on surcharging after these five states, but it is included in the "control” group because its ban was lifted well before Iowa lifted its ban. The surveys referred to here were conducted by Moebs Services, of Lake Bluff, Illinois, under contract with the Federal Reserve Board. The samples of banks surveyed by Moebs Services were obtained through random sampling.
} 


\section{$4 \quad$ The empirical model}

The approach taken in this paper is to conduct separate comparisons of the pre- and postintervention states, where the pre-intervention state is measured as of 2000 and the postintervention state is measured as of 2003 and, separately, as of 2004. This approach is dictated by the years for which extensive bank-specific data on ATM deployments are available. Because it compares only one pre-intervention period with one post-intervention period, it also avoids some of the biases that, according to Bertrand, Duflo, and Mullainathan (2004), have plagued many recent applications of difference-in-difference analyses. Separation of the comparisons of the year 2000 with 2003 and of the year 2000 with 2004 also allows a relatively agnostic look at the time it takes for changes in ATM deployments to take place.

More formally, consider the following general relationship:

$$
a t m_{i k}^{t}=\beta_{0}^{t} e^{\beta_{1} \text { surcharge }^{t}}\left(X_{i k}^{t}\right)^{\beta_{2}} \varepsilon_{i k}^{t}
$$

which expresses the ATM deployment of bank $i$ in state $k$ at time $t, a^{t} t_{i k}^{t}$, as a function of a dummy variable, denoted surcharge $e^{t}$, that receives the value of one if at time $t$ the bank operates in a state that allows surcharging and zero if at time $t$ it does not, and a vector of time-varying characteristics of bank $i$ in state $k$ at time $t$, denoted $X_{i k}^{t} \cdot \beta_{0}^{t}$ denotes a constant relevant to time t, $\beta_{1}$ and $\beta_{2}$ denote coefficients or coefficient vectors, and $\varepsilon_{i k}^{t}$ is an error term, assumed to be distributed log normal.

A multiplicative form is assumed for this relationship, since it seems more plausible that a change in surcharge ${ }^{t}$ or $X_{i k}^{t}$ would affect the ATM deployment of banks of widely differing sizes equally in percentage terms, rather than in absolute terms (as would be implied by the simple linear functional form). This functional form also allows results to be presented in a way that is less sensitive to a potentially important confounding difference between Iowa and its neighbors, as discussed below.

Taking the natural log of (1) and first differencing yields:

$$
\ln \left(a_{t m}^{t} / a_{i k}^{t-1}\right)=\left(\ln \beta_{0}^{t}-\ln \beta_{0}^{t-1}\right)+\beta_{1} l i f t b a n_{t-1}^{t}+\beta_{2} \ln \left(X_{i k}^{t} / X_{i k}^{t-1}\right)+\left(\ln \varepsilon_{i k}^{t}-\ln \varepsilon_{i k}^{t-1}\right)
$$

where liftban $_{t-1}^{t}$, defined as surcharge surcharge $_{t-1}$, is a dummy variable that receives the value of one if the bank operates in a state that imposed a surcharge ban at time t- 1 but not at $t$, and zero if it operates in a state where a surcharge ban was not imposed during either time period. ${ }^{6}$ Other explanatory variables to be employed in the analysis include a measure of the change in the population over time in the markets in which each institution operates, a measure of the change in the number of deposit accounts of the bank over time (in some regressions), and an indicator of the extent to which the bank operates in urban areas.

The strength of this approach is that it controls for any time-invariant bank or state characteristic or for any characteristic for which the change from time $t-1$ to time $t$ is the same for all observations. The choice of a sample that is restricted to one area of the country, as well as other restrictions to be discussed below, is made to take fullest advantage of this form of statistical control.

\footnotetext{
${ }^{6}$ The case in which a surcharge ban was in effect at the later time period but not in effect at the earlier time period and the case in which a surcharge ban was imposed in both time periods are not observed.
} 


\section{$5 \quad$ Data}

The data on bank ATM deployment were obtained from Thompson Financial Publishing for the years 2000, 2003, and 2004. The data set from which this information is obtained is designed to be a census of all banks, rather than simply a survey. This is particularly desirable for the purposes of this investigation, because it is, by design, restricted to one section of the country. Missing and inadequately updated data are a concern in the use of the ATM item from this data set, however, because not every institution appears to report or update regularly. These problems appear to afflict a minority of institutions covered in the data, however, and there is little reason to believe that omissions or failures to update are systematically related to surcharge status. To minimize problems associated with measurement error, banks that report no ATMs are excluded from the analysis, since many banks designated as having no ATMs appear to have instead not reported. Institutions that operate in more than one state are also excluded, because there is no way to determine, short of extrapolation, their deployment of ATMs in each state. Also, for purposes of comparison with Iowa, banks with more than $\$ 2.5$ billion in assets are excluded, because no single-state institution exceeded that size in Iowa during the period studied. Further, since metropolitan areas the size of Chicago, Kansas City, St. Louis, Minneapolis-St. Paul, and Milwaukee are not found in Iowa, institutions in these large metropolitan areas are also excluded.

Information on ATM deployment is available from this source on about 2,090 institutions operating in Iowa or in the states neighboring Iowa. After exclusions (primarily of the very small banks for which the ATM deployment is reported to be zero), usable information is available for approximately 1,400 financial institutions. Of these, 295 institutions are located in Iowa, and the remaining institutions are located in the six states neighboring Iowa.

The ATM data available from this data set refer to the number of separate ATM locations of the bank rather than the number of ATMs that the bank owns. This measure is probably more relevant to assessments of the welfare implications of surcharging, since it should be a better measure of the convenience that a bank offers its customers through its ATM deployment. In those few cases in which a merger between two banks occurred during the comparison periods, the numbers of ATM locations of the two banks in 2000 are summed, so that the resulting number may be compared with the number of ATM locations of the merged entity in 2003 or 2004.

Another issue associated with the use of these data concerns the presence of a few substantial outliers. While 95 percent of the observations entail changes in the number of ATM locations of five or less between 2000 and 2004, one bank reported a reduction in the number of ATM locations of 48. A call to this and other institutions reporting substantial changes revealed that these changes typically resulted from the sale of a large number of ATMs from one bank to another (or to several institutions). Because the other side of these transactions is presumably reflected in the data, these outliers are not excluded from the data set. Exclusion from the data set of all institutions reporting a change of more than five ATM locations (not reported) was found to yield results that are equivalent to those reported below, with, if anything, higher t-statistics. Data used to measure the explanatory variables employed in the analysis were obtained from the Consolidated Reports of Condition and Income, available for each institution, the FDIC's Summary of Deposits, 
which provides information on the location and total deposits of each branch of each bank in the county, and the US Census of Population.

\section{$6 \quad$ Results}

Table 1 presents relevant summary statistics. The first two rows present the percent changes in the number of ATM locations observed over the 2000-2003 and 2000-2004 periods for Iowa and, separately, for the states neighboring Iowa. These percent changes are calculated as the change in the total number of ATM locations observed for the sample, divided by the total number of ATM locations in 2000 (and multiplied by 100). Only those institutions for which valid ATM deployment data are available for both years (2000 and 2003 for the 2000-2003 period and 2000 and 2004 for the 2000-2004 period) are used in these calculations. These "raw" figures suggest that ATM deployment increased by more in Iowa than in neighboring states, consistent with the hypothesis that the lifting of the surcharge ban in Iowa in March of 2002 provided incentives for increased ATM deployment in that state.

\begin{tabular}{|l|l|l|}
\hline & Iowa & States neighboring Iowa \\
\hline Percent Change in Total ATM Locations, 2000-2003 & 16.1 & 13.8 \\
\hline Percent Change in Total ATM Locations, 2000-2004 & 24.8 & 16.1 \\
\hline Mean Number of Accounts, 2000 & 7,874 & 8,401 \\
\hline Mean Assets, 2000 (in \$ million) & 89.9 & 94.1 \\
\hline Mean Number of Branches, 2000 & 2.57 & 2.85 \\
\hline
\end{tabular}

Table 1: Summary statistics

Note: All statistics exclude financial institutions with greater than $\$ 2.5$ billion in assets (the largest headquartered in Iowa) and financial institutions operating in metropolitan areas substantially larger than those found in Iowa--excluded a priori to make institutions in the "control group" more comparable to institutions in Iowa. Financial institutions that operate in more than one state are also excluded. ${ }^{1}$ Calculated for financial institutions reporting ATM locations in both years.

These data also suggest that it takes some time for the impact of surcharge authority on ATM deployment to be registered. By 2003, the number of ATM locations in Iowa had increased by 16.1 percent since 2000, while it had increased by 13.8 percent in the states neighboring Iowa. By 2004, however, this small difference had widened somewhat. By that year, the number of ATM locations in Iowa had increased by 24.8 percent, while the number increased by only 16.1 percent in the states neighboring Iowa.

It is also apparent from table 1 that the number of separate ATM locations offered by financial institutions increased substantially in the whole region. These figures suggest that, while the lifting of surcharge restrictions in Iowa provided an impetus for ATM deployment in that state, most of the observed changes in ATM deployment occurring over this period came about for reasons unrelated to surcharge authority.

The last three rows in table 1 present the average number of accounts, the average asset size, and the average number of branches, respectively, of financial institutions in Iowa and in the states neighboring Iowa in 2000, the beginning of the period studied. As indicated, financial institutions in the states neighboring Iowa were on average slightly 
larger than those in Iowa, although only the difference of .28 in the average number of branches was found to be statistically significant. ${ }^{7}$

The results presented in table 1 do not control for potentially important bank-specific and market-specific characteristics that could influence a bank's decision to deploy ATMs. The extent to which a bank operates in metropolitan areas, the growth in the markets in which it operates, and growth in the size of the bank over time are all characteristics that might be associated with observed changes in the number of ATM locations that an institution provides depositors.

\begin{tabular}{|c|c|}
\hline Name & Definition \\
\hline iowa & $\begin{array}{l}\text { A binary variable set equal to one if the institution operates in Iowa and } \\
\text { zero otherwise. }\end{array}$ \\
\hline acctnum $_{t}$ & $\begin{array}{l}\text { Number of deposit accounts of the bank at time t, employed as a measure } \\
\text { of bank size. }\end{array}$ \\
\hline acctquarti & $\begin{array}{l}\text { A binary variable set equal to one if the number of accounts of the banks } \\
\text { places the bank in the ith quartile of the sample, as measured by the } \\
\text { number of deposit accounts, and zero otherwise. }\end{array}$ \\
\hline $\operatorname{atm}_{t}$ & The number of ATM locations provided by the bank at time t. \\
\hline wmsa & $\begin{array}{l}\text { The weighted average of a binary variable that receives the value of one if } \\
\text { the bank operates in a Metropolitan Statistical Area (MSA) and zero if it } \\
\text { operates in a county outside an MSA, where, in case the bank operates in } \\
\text { more than one area, the share of the bank's branches in each area serves as } \\
\text { the weight. }\end{array}$ \\
\hline wpop $_{t}$ & $\begin{array}{l}\text { The weighted average of the population, at time t, of the market in which } \\
\text { the bank operates, where, in case the bank operates in more than one } \\
\text { market, the share of the bank's branches in each market serves as the } \\
\text { weight. }\end{array}$ \\
\hline
\end{tabular}

\section{Table 2: Variable definitions}

Below, we present the results of OLS regressions designed to control for these factors. The dependent and explanatory variables in these regressions are constructed from the variables listed and defined in table 2. These include the variable Iowa, which is a dummy variable indicating operation in Iowa. This variable is equivalent to the variable liftban $_{t-1}^{t}$ in (2), since only the Iowa banks in the sample experienced the lifting of the surcharge ban over the period studied. The variable $a t m_{t}$ denotes the number of ATM locations of the bank at time $t$, and acctnum $_{t}$, defined as the number of deposit accounts of the bank, is a measure of bank size thought to be the most relevant in explaining ATM deployment. The variables denoted acctquarti (acctquart1 through acctquart4) are dummy variables indicating that the bank falls into the $\mathrm{i}^{\text {th }}$ quartile of acctnum $_{t-1}$. These variables are used to investigate the extent to which the impact of the lifting of a surcharge ban influences the ATM deployment of banks of different sizes. Finally, wmsa and wpop $p_{t}$ indicate the extent

\footnotetext{
${ }^{7}$ As described above, banks in the states neighboring Iowa exclude banks with over $\$ 2.5$ billion in assets (the largest observed in Iowa) and institutions operating in metropolitan areas substantially larger than those found in Iowa. These institutions are excluded a priori to make institutions in the "control group" more comparable to institutions in Iowa.
} 
to which the bank operates in metropolitan areas and the population at time $t$ of the market in which the bank operates, respectively. Because a bank may operate in more than one market, these variables are weighted according to the shares of the bank's branches in each of the markets in which it operates.

\begin{tabular}{|c|c|c|c|c|c|}
\hline & (1) & $(2)$ & (3) & (4) & (5) \\
\hline \multirow[t]{2}{*}{ constant } & .11 & .10 & .099 & .10 & .10 \\
\hline & $(11.61)$ & $(8.94)$ & $(8.90)$ & (9.13) & $(9.40)$ \\
\hline \multirow[t]{2}{*}{ Iowa } & $.036^{+}$ & $.039^{+}$ & $.038^{+}$ & & \\
\hline & $(1.68)$ & $(1.81)$ & $(1.78)$ & & \\
\hline \multirow[t]{2}{*}{ Iowa*acctquart1 } & & & & -.0019 & -.018 \\
\hline & & & & $(-.04)$ & $(.-.38)$ \\
\hline \multirow[t]{2}{*}{ Iowa*acctquart2 } & & & & .010 & .011 \\
\hline & & & & $(.24)$ & $(.26)$ \\
\hline \multirow[t]{2}{*}{ Iowa*acctquart3 } & & & & .042 & .044 \\
\hline & & & & $(1.06)$ & $(1.12)$ \\
\hline \multirow[t]{2}{*}{ Iowa*acctquart4 } & & & & $.075^{+}$ & $.078^{+}$ \\
\hline & & & & $(1.77)$ & $(1.85)$ \\
\hline \multirow[t]{2}{*}{ wmsa } & & $.052^{*}$ & $.049^{*}$ & $.051^{*}$ & $.045^{* *}$ \\
\hline & & $(2.40)$ & $(2.25)$ & $(2.36)$ & $(2.09)$ \\
\hline \multirow[t]{2}{*}{$\ln \left(w p o p_{t} / w p o p_{t-1}\right)$} & & & $.30^{+}$ & $.30^{+}$ & $.30^{+}$ \\
\hline & & & $(1.89)$ & $(1.82)$ & $(1.91)$ \\
\hline \multirow[t]{2}{*}{$\ln \left(\right.$ acctnum $_{t} /$ acctnum $\left._{t-1}\right)$} & & & & & $.14^{* *}$ \\
\hline & & & & & (3.91) \\
\hline $\mathrm{R}^{2}$ & .002 & .006 & .009 & .010 & .021 \\
\hline $\mathrm{N}$ & 1429 & 1429 & 1367 & 1367 & 1367 \\
\hline
\end{tabular}

Table 3: Changes in the number of ATM locations of financial institutions in Iowa and in the states neighboring Iowa, 2000-2003

Note: Dependent variable is $\ln \left(\mathrm{atm}_{t} / \mathrm{atm}_{\mathrm{t}-1}\right)$. t-statistics are in parentheses. The symbols + , *, and ** denote statistical significance at the 10,5 , and 1 percent levels, respectively.

Tables 3 and 4 present the results of OLS regressions: table 3 reports regression results obtained for the 2000-2003 comparison, while table 4 reports the results obtained for the 
2000-2004 comparison. Consistent with equation (2), the dependent variable in these regressions is $\ln \left(\mathrm{atm}_{\mathrm{t}} / \mathrm{atm}_{\mathrm{t}-1}\right)$. The first column of table 3 presents results obtained when only Iowa is used as an explanatory variable. As indicated, its coefficient is positive and barely significant at the 10 percent level. Comparison of its magnitude with that of the constant term suggests that operation in Iowa was associated with a growth in ATM deployment that was about a third greater in Iowa than in the neighboring states. The addition of wmsa in column (2) and $\ln \left(w p o p_{t} / w p o p_{t-1}\right)$ in column (3) indicates that operation in a metropolitan area and in a market with faster population growth was associated with faster growth in ATM deployment over this period. The addition of these variables to the regression make no material difference to the registered positive impact of operation in Iowa, consistent with the hypothesis that the lifting of the surcharge ban there (and not in neighboring states) caused ATM deployment to increase.

Column (4) presents the results of a regression in which Iowa is replaced with four variables indicating the interaction of Iowa with dummy variables indicating the quartile of initial bank size (measures as acctnum $_{t-1}$ ) to which the observed bank belongs. This specification is designed to determine if the impact of the lifting of the surcharge ban in Iowa influenced the change in ATM deployment of Iowa banks in a way that depends on the initial size of the bank. As indicated, coefficient magnitudes increase as one moves from the first to the fourth quartile of size, but only the interaction associated with the largest quartile is statistically significant (and only at the 10 percent level). ${ }^{8}$ The coefficient of this term is approximately twice as large as that observed for Iowa banks in general. Thus, results presented thus far are consistent with the hypothesis that the lifting of the surcharge ban in Iowa had a fairly substantial impact on ATM deployment in that state, and this impact (in terms of the percentage change in ATM locations) appears to have been greater for the largest quartile of banks than for smaller banks. Relevant coefficients, however, are statistically significant only at the 10 percent level.

The final regression reported in table 3 adds an explanatory variable that indicates the change in the bank's size over the period, measured as $\ln \left(\right.$ acctnum $_{t} /$ acctnum $\left._{t-1}\right)$. This specification is included last because the inclusion of this variable could introduce endogeneity bias if growth in ATM deployment influences the number of accounts of the bank over time or if some unobservable characteristic of the bank influences both ATM deployment and the number of accounts. While its coefficient is positive and highly significant, its inclusion does not appear to alter the coefficients of the other variable in the analysis in any meaningful way.

Table 4 reports the results of the same regressions for the longer 2000-2004 period. As indicate in columns (1) through (3), the coefficients of Iowa are positive and highly significant in these regressions, with magnitudes that are roughly twice those observed for the 2000-2003 period. As in the case of the results presented in table 1, this suggests that it takes some time for the full impact of the lifting of a surcharge ban to be reflected in ATM deployment. The positive coefficients of wmsa and $\ln \left(w p o p_{t} / w p o p_{t-1}\right)$ are equivalent in

\footnotetext{
${ }^{8}$ The coefficient of the interaction of Iowa with a continuous measure of firm size (not reported) is positive with a t-statistic of 1.60. The coefficient of this term obtained for the 2000-2004 comparison (also not reported) is positive and statistically significant.
} 


\begin{tabular}{|c|c|c|c|c|c|}
\hline & (1) & (2) & (3) & (4) & (5) \\
\hline \multirow[t]{2}{*}{ constant } & .16 & .15 & .14 & .14 & .14 \\
\hline & $(13.23)$ & $(10.58)$ & $(9.79)$ & $(10.16)$ & $(10.75)$ \\
\hline \multirow[t]{2}{*}{ Iowa } & $.069^{* *}$ & $.071^{* *}$ & $.077^{* *}$ & & \\
\hline & $(2.63)$ & $(2.73)$ & $(2.99)$ & & \\
\hline \multirow[t]{2}{*}{ Iowa*acctquart1 } & & & & -.0034 & -.043 \\
\hline & & & & $(-.06)$ & $(.-.77)$ \\
\hline \multirow[t]{2}{*}{ Iowa*acctquart2 } & & & & $.091^{+}$ & $.095^{+}$ \\
\hline & & & & (1.77) & (1.87) \\
\hline \multirow[t]{2}{*}{ Iowa*acctquart3 } & & & & .055 & .057 \\
\hline & & & & $(1.11)$ & $(1.15)$ \\
\hline \multirow[t]{2}{*}{ Iowa*acctquart4 } & & & & $.12^{*}$ & $.12^{*}$ \\
\hline & & & & $(2.25)$ & $(2.32)$ \\
\hline \multirow[t]{2}{*}{ wmsa } & & $.050^{+}$ & $.043^{+}$ & $.048^{+}$ & $.040^{+}$ \\
\hline & & $(1.86)$ & $(1.67)$ & $(1.84)$ & $(1.81)$ \\
\hline \multirow[t]{2}{*}{$\ln \left(w p o p_{t} / w p o p_{t-1}\right)$} & & & $.31^{+}$ & $.31^{+}$ & $.30^{+}$ \\
\hline & & & (1.88) & $(1.86)$ & $(1.81)$ \\
\hline \multirow[t]{2}{*}{$\ln \left(\right.$ acctnum $_{t} /$ acctnum $\left._{t-1}\right)$} & & & & & $.23^{* *}$ \\
\hline & & & & & $(5.43)$ \\
\hline $\mathrm{R}^{2}$ & .005 & .007 & .011 & .011 & .033 \\
\hline $\mathrm{N}$ & 1404 & 1404 & 1318 & 1318 & 1318 \\
\hline
\end{tabular}

Table 4: Changes in the number of ATM locations of financial institutions in Iowa and in the states neighboring Iowa, 2000-2004

Note: Dependent variable is $\ln \left(\mathrm{atm}_{t} / \mathrm{atm}_{\mathrm{t}-1}\right)$. t-statistics are in parentheses. The symbols + , * and $* *$ denote statistical significance at the 10,5 , and 1 percent levels, respectively.

magnitude to those reported in table 3, although the coefficients of wmsa are statistically significant at a lower level in these regressions. As in table 3, the coefficients of the interaction of Iowa with dummy variables indicating the four size quartiles suggest that the lifting of the surcharge ban had a greater positive impact on the growth rate of ATM deployment for banks falling in the highest size quartile. The coefficient of Iowa*acctquart4 in column (4) is greater in both magnitude and in statistical significance than that reported in table 3 for the shorter period. Also as reported in table 3 , the 
coefficient of $\ln \left(\right.$ acctnum $_{t} /$ acctnum $\left._{t-1}\right)$ in column (6) of table 4 is positive and highly significant, and the inclusion of this potentially endogenous variable makes no material difference to the results associated with the other variables included in the regression.

In both tables 3 and 4 , reported $\mathrm{R}^{2}$ s are extremely low. We can think of two possible reasons for this. First, while the data include roughly one hundred different distinct values of the dependent variable, this is far less than the approximately 1,400 observations employed in each regression. The reason is the inherent discreteness of any change in the number of ATM locations. The assumption of a continuous relationship will, for most observations, result in a difference between the predicted and actual values of the dependent variable (and therefore a lower $\mathrm{R}^{2}$ ) that results because of this discreteness. Second, as noted above, the data contain a number of cases of substantial bank-specific changes in the number of ATM locations that result simply because of a sale or transfer of ATMs from one bank to another in the same state. While there is little reason to believe that these transfers will bias the coefficients of state-specific dummy variables, there is every reason to believe that they will result in unexplained bank-specific variation (and therefore low $\mathrm{R}^{2} \mathrm{~s}$ ) in the regressions reported in tables 3 and 4 .

Another issue concerns whether banks in each of the six states that neighbor Iowa exhibit, on average, a smaller increase in the percent change in ATM locations than do banks in Iowa (rather than just the aggregation of banks in these states) and whether the behavior of banks in these states appears to be similar to each other - a desirable feature of an appropriate "control group." These issues were investigated by replacing Iowa with six dummy variables, each indicating operation in one of the six neighboring states, and reestimating regressions (1) through (3) for the 2000-2003 and 2000-2004 time periods. With operation in Iowa serving as the omitted category, all coefficients of the state dummy variables were found to be negative in each of these regressions, consistent with slower growth in ATM locations (compared to Iowa) in each of these states. Not all of these coefficients, however, were found to be statistically significant. In four of these six regressions, F-tests fail to reject the equality of these six coefficients. F-tests were found to yield marginal significance in the case of estimations for the 2000-20004 period that do not control for population growth - a result of a particularly strong negative effect observed for the state of Nebraska. ${ }^{9}$

\subsection{A possible confounding effect}

While a difference-in-difference analysis such as this one offers major advantages over the more typical cross-sectional econometric approach, an obvious concern is the possibility that results are confounded by the influence of unmeasured factors over time that might differ between Iowa and its neighbors. A relevant concern in this regard relates to the fact that Iowa restricts ATM ownership to financial institutions, while the states neighboring Iowa do not. Thus, independent service operators (ISOs) are free to establish ATM networks in the states neighboring Iowa, but not in Iowa.

Although no change in this restriction occurred over the study period either in Iowa or in the states neighboring Iowa, this distinction could bias the comparison between Iowa and its neighbors under certain circumstances. Table 1 (and the magnitude of the positive intercepts reported in table 3 and 4) indicates that bank ATM deployment rose over the study period in the states neighboring Iowa. If the same unobservable factors that caused

\footnotetext{
${ }^{9}$ Results are available from the authors upon request.
} 
ATM deployment by financial institutions in these states to increase also caused ISO ATM deployment to increase, then competition for locations and customers by the ISOs could have retarded the growth of bank ATM deployment in these states, biasing upward the reported difference attributed to the lifting of the Iowa surcharge ban.

Because banks, unlike ISOs, gain rents by increasing their base of depositors, it is unlikely that an ISO would outbid a bank for any location that is desirable to a bank. But competition from ISOs may well reduce demand for use of a bank's ATMs on the part of nondepositors, and this could make bank ATM deployment less attractive.

Our specification of the change attributable to the lifting of surcharge bans as a proportionate change, rather than an absolute change, is the primary way that we address this issue. If competition from ISOs does retard bank ATM deployment, this should be true in the states neighboring Iowa both at time $t$ and at time $t-1$. The question then is how this depressing effect of ISO competition would have changed between the two periods. If, as seems most probable, ISO ATM deployment grew at about the same rate as bank ATM deployment, then the growth in ISO competition would probably not materially affect the growth in bank ATM deployment when expressed in percentage terms. ${ }^{10}$ Absent any more definitive information on ISO ATM networks and the competitive responses of banks to them, we can only note that this issue is a potential qualification to our results and that our focus on the proportionate change in bank ATM deployment makes that qualification less of an issue.

\section{Conclusion}

In this paper, we examine empirically the relationship between incompatibility among networks and the extent to which firms invest in improving their products. Focusing on ATM networks in the banking industry, the measure of product quality in this case is the number of ATM locations that banks offer to potential users, and the measure of incompatibility is the charge incurred by depositors to use the ATMs of another bank. The so-called surcharge, levied by the owner of the ATM in such transactions, is particularly advantageous for such an analysis, since differences in state regulation allow such an analysis to be more easily implemented.

The statistical approach employed is that of a "difference-in-difference" analysis, wherein changes in bank-specific ATM deployment occurring in Iowa over a period in which its surcharge ban was lifted are compared to equivalently measured changes occurring over the same time period in neighboring states, where no change in surcharge restrictions occurred. Results suggest that the authority to surcharge does indeed result in deployment of more ATMs by the banking industry. Measured as the difference in the percent change in ATM locations over time, the difference appears to be substantial, particularly for the longer time period examined. We also find evidence that larger Iowa banks added more ATM locations, in percentage terms, than did smaller Iowa banks after lifting of the surcharge ban, all else equal. Results also reveal that operation in urban areas and operation in markets with faster population growth were positively related to bankspecific percentage increases in ATM deployment during the periods examined.

\footnotetext{
${ }^{10}$ It is more probable that growing ISO competition would retard bank ATM deployment in absolute terms.
} 
In most markets, issues of compatibility and standards are determined as competitive outcomes or by coordination within standard-setting bodies or other mechanisms. In the case of ATM surcharging, the ability to introduce incompatibilities between banks' products is an issue of public policy. In this instance, the results reinforce the notion that policy must consider not only the direct effects of incompatibility on consumers, but also the induced effect on investment, or more generally on product quality and innovation.

\section{$8 \quad$ References}

Bernhardt, Dan and Nadia Massoud (2002) “'Rip-Off' ATM Surcharges,” Rand Journal of Economics, 33: 96-115.

Bernhardt, Dan and Nadia Massoud (2005) "Endogenous ATM Location and Pricing," SSRN Working Paper, http://ssrn.com/abstract=899460

Bertrand, Marianne, Esther Duflo, and Sendhil Mullainathan (2004) "How Much Should We Trust Differences-in-Differences Estimates?” Quarterly Journal of Economics, 119: 249-275.

Farrell, Joseph and Garth Saloner (1985) "Standardization, Compatibility, and Innovation,” Rand Journal of Economics, 16: 70-83.

Gowrisankaran, Gautam and John Krainer (2006) "The Welfare Consequences of ATM Surcharges: Evidence from a Structural Entry Model,” NBER Working Paper \#12443, August.

Hannan, Timothy, Elizabeth Kiser, Robin Prager and Jamie McAndrews (2003) "To Surcharge or Not to Surcharge: An Empirical Investigation of ATM Pricing," Review of Economics and Statistics, 85: 990-1002.

Hannan, Timothy (2002) “Retail Fees of Depository Institutions, 1997-2001,” Federal Reserve Bulletin 88(September): 405-413.

Ishii, Joy (2005) “Compatibility, Competition, and Investment in Network Industries: ATM Networks in the Banking Industry,” Working Paper, Stanford University, October.

Katz, Michael and Carl Shapiro (1985) "Network Externalities, Competition, and Compatibility,” American Economic Review, 75:424-440.

Knittel, Christoper R. and Victor Stango (2004) "Incompatibility, Product Attributes and Consumer Welfare: Evidence from ATMs,” NBER Working Paper \#10962, December. 